\title{
Current updates in machine learning in the prediction of therapeutic outcome of hepatocellular carcinoma: what should we know?
}

\author{
Zhi-Min Zou', De-Hua Chang ${ }^{2}$, Hui Liu ${ }^{1}$ and Yu-Dong Xiao ${ }^{1^{*}}$ (1)
}

\begin{abstract}
With the development of machine learning (ML) algorithms, a growing number of predictive models have been established for predicting the therapeutic outcome of patients with hepatocellular carcinoma (HCC) after various treatment modalities. By using the different combinations of clinical and radiological variables, ML algorithms can simulate human learning to detect hidden patterns within the data and play a critical role in artificial intelligence techniques. Compared to traditional statistical methods, ML methods have greater predictive effects. ML algorithms are widely applied in nearly all steps of model establishment, such as imaging feature extraction, predictive factor classification, and model development. Therefore, this review presents the literature pertaining to ML algorithms and aims to summarize the strengths and limitations of $\mathrm{ML}$, as well as its potential value in prognostic prediction, after various treatment modalities for HCC.
\end{abstract}

Keywords: Hepatocellular carcinoma, Machine learning, Predictive, Modality

\section{Key points}

1. To highlight the effectiveness of machine learning algorithm on the prediction of therapeutic outcome for hepatocellular carcinoma after various treatment modalities

2. To illustrate the advantages and disadvantages of each machine learning algorithm

3. To familiarize the challenges of selecting a machine learning algorithm when creating a model

\footnotetext{
${ }^{*}$ Correspondence: xiaoyudong222@csu.edu.cn

1 Department of Radiology, The Second Xiangya Hospital of Central South University, No.139 Middle Renmin Road, Changsha 410011, China

Full list of author information is available at the end of the article
}

\section{Introduction}

Hepatocellular carcinoma (HCC) is an aggressive tumor which remains the second-most frequent cause of cancer death worldwide [1-3]. According to the different statuses of patients with HCC, several guidelines [4-7] recommend various treatment strategies. Due to the aggressive biological behavior of $\mathrm{HCC}$, recurrence is not uncommon. Therefore, it is essential to predict therapeutic outcomes prior to treatment so that physicians can design a personalized therapeutic strategy for each patient. The conventional process of model establishment is selecting the appropriate predictors, utilizing them for statistical analysis and ultimately deriving a multivariate predictive model [8-12]. However, predictive models developed by traditional statistical methods, such as the logistic regression (LR) model and Cox proportional hazards model, are not reliable because the factors included in the models are too simple and utilize a low evidence level. Machine learning (ML) is a powerful tool 
for generating high-level medical features or combining quantitative radiomic parameters with efficient algorithms [13-16]. ML algorithms simulate human learning to detect hidden patterns within $\mathrm{HCC}$ therapeutic data that are clearer than those derived from traditional statistical methods. With this in mind, ML algorithm has been used in many studies to predict the therapeutic outcome of HCC patients. Thus, in this review, the advantages and disadvantages of each ML algorithm are clarified, and relevant literature on the prediction of therapeutic outcomes after various treatment modalities for HCC is described.

\section{Advantages and disadvantages of the ML algorithm}

ML algorithms have several advantages over traditional statistical methods. First, traditional statistical methods can only process the variables that have a linear relationship with the outcome [12], whereas ML algorithms have the ability to process nonlinear data. Second, ML algorithms can learn from existing data to find novel patterns between variables and generate predictions [17-20]. Third, the ML model may contain more variables [21, 22] since the variables do not simply rely on the selection of traditional statistical methods [23-25]. Last, ML methods can process big data at a high speed.

Although ML algorithms are increasingly used, the disadvantages of ML algorithms should be kept in mind. First, the current ML methods are still not readily available for clinical practice, and the design of the ML model is not standard. Second, the lack of perfect generalization capability is still a common issue in clinical practice. The detailed advantages and disadvantages of the ML algorithm are listed in Table 1.

\section{ML models in the prediction of therapeutic outcomes for HCC}

With the development of ML algorithms, a growing number of studies have developed prognostic predictive models for HCC using the ML method. Therefore, understanding how ML works is essential. In this section, various ML models are introduced.

\section{Neural networks}

Neural networks are a classic ML method that simulates human brain neural networks. The most widely used neural networks are artificial neural networks (ANNs) and deep neural networks (DNNs). ANN [26] is one of the earliest neural network models and can be divided into three components: an input layer, a hidden layer, and an output layer. The ANN model can include a perceptron or a multilayer perceptron (MLP) (Fig. 1), with or without a hidden layer. However, ANNs cannot directly deal with medical imaging. With the development of deep learning, DNNs are widely used in establishing models [27]. Convolutional neural networks (CNNs) $[28,29]$ are one of the most common DNNs that can automatically identify and segment medical imaging. Another type of DNN is the recurrent neural network (RNN). However, RNNs are limited in HCC prognostic studies because the RNN algorithm cannot process data over a large time span.

\section{Support vector machines}

A support vector machine (SVM) [30] is a type of twocategory model aimed at finding the optimal separating hyperplane with the largest distance to the support vector of any class (Fig. 2). Due to the hyperplane concept, SVM is often used for the selection of parameters for which the parameters are selected by the correlation to the results. However, SVMs are only applied in studies with small sample sizes, as the number of support vectors in large datasets is still very big, which may increase the complexity and training time of SVM algorithms.

\section{Decision tree and random forest}

The decision tree (DT) [31] is easy to understand and adopts a form of yes or no question and comprises a root node, parent node and leaf node/terminal node. Unfortunately, with the increasing complexity of the

Table 1 Advantages and disadvantages of ML algorithm

\begin{tabular}{|c|c|}
\hline & Content \\
\hline Advantages & $\begin{array}{l}\text { It can process a big data } \\
\text { It can process a nonlinear data } \\
\text { It can be used to select meaningful predictive variables and extract radiomic variables } \\
\text { It usually has higher predictive performance than traditional statistical model }\end{array}$ \\
\hline Disadvantages & $\begin{array}{l}\text { The accurate selection of ML algorithms is a challenge to establish a predictive model } \\
\text { The design of ML predictive models lacks standards } \\
\text { It is difficult to identify the process of ML model development due to the existence of } \\
\text { "black box" } \\
\text { The generalization ability of the established model needs to be further confirmed in } \\
\text { validation cohort }\end{array}$ \\
\hline
\end{tabular}




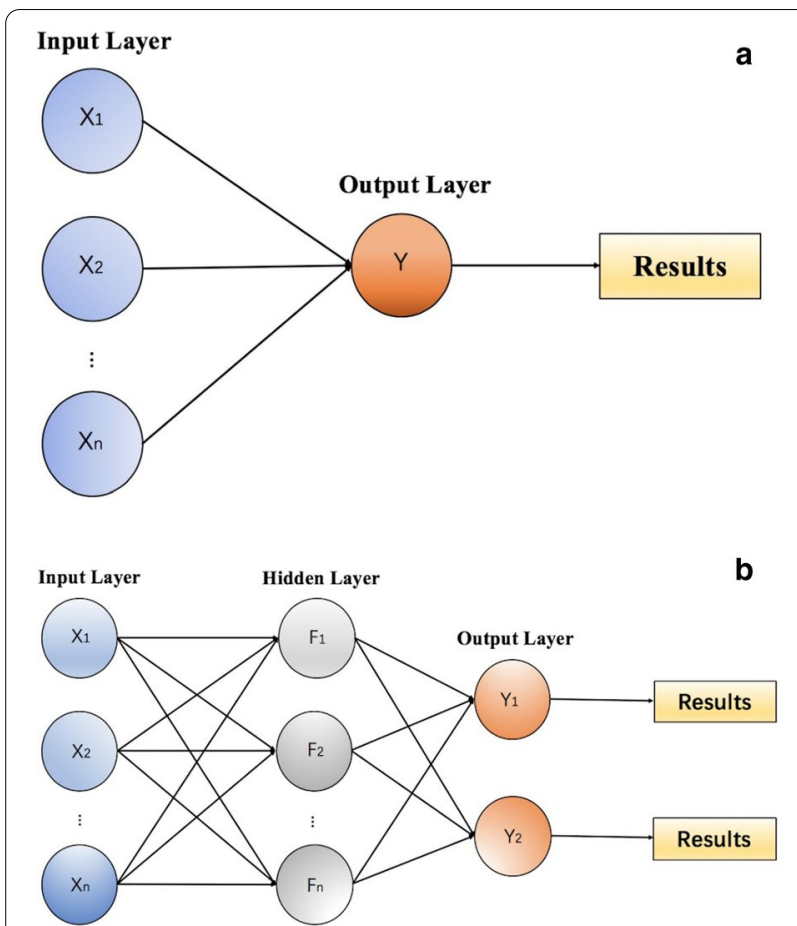

Fig. 1 Schematic diagram of an artificial neural network (ANN). a shows a schematic diagram of a perceptron. It is the simplest model of an ANN and only includes an input layer and an output layer. In the perceptron, the input feature parameters are directly converted to the output results through the weight between the input and output. $\mathbf{b}$ shows a schematic diagram of a 3-layer ANN (also called a multilayer perception). The first layer is the input layer, corresponding to the input feature parameters $(\mathrm{X})$; the middle is the hidden layer, which uses a composite function to achieve the abstraction for input features so that the input can be better divided linearly; the last is the output layer, where the number of categories to be classified determines the number of neurons in this layer, and its output value $(Y)$ is the predictive value of the ANN
DT model, the predictive value inevitability decreases. Random forest (RF) [32] represents an ensemble learning approach of multiple unique DTs, which is designed to increase the predictive performance (Fig. 3). In the training procedure, the bootstrap sampling method is used to construct each tree based on randomized samples and features from the original dataset, and the final result of the RF is the average prediction of each tree. In most ML algorithms, RFs have the highest predictive performance [33]. Ishwaran et al. [34] designed random survival forests (RSFs), an extension of RFs to rightcensored survival data. However, due to the complexity of $\mathrm{RF}$, the processing requires more time for training the model compared with other ML algorithms.

\section{Bayesian networks}

Bayesian networks (BNs) [35] are different from most ML algorithms. A BN is an extension of Bayes' theorem and presents the causality under each variable via a directed acyclic graph (Fig. 4). Therefore, those algorithms can visualize information. $\mathrm{BNs}$ have been applied to analyze predictors for survival in postsurgical HCC patients through conditional probability tables (CPTs) [36]. However, the relationship between each variable in the $\mathrm{BN}$ model is not always clear, which leads to low accuracy.

\section{Methods}

A search of PubMed was conducted for a prognostic predictive model for HCC published from January 1995 to May 2020. The following search algorithm was created: "hepatocellular carcinoma" and "model" and "predict" or "prognostic/prognosis" and "machine learning" or "neural network" or "support vector machine" or "decision tree" or "random forest" or "Bayesian network". Initially, a total of 291 relevant research articles were searched, and the literature selection process is shown in Fig. 5. Ultimately, 29 articles were enrolled in the final analysis.

\section{Prediction of therapeutic outcomes by various treatment modalities}

There are various treatment options for HCC. Surgical resection, ablative therapy, and liver transplantation (LT) are potentially curative treatments, and transarterial chemoembolization (TACE) and sorafenib are palliative treatments [37-40]. Due to the poor prognosis of HCC patients, it is essential to create a suitable predictive model for predicting therapeutic outcomes prior to treatment. In this section, the current updates of ML algorithms are reviewed for various treatment modalities in HCC patients.

\section{Surgical resection}

Partial hepatectomy remains the mainstay of curative treatment in the early stage of HCC. Intrahepatic recurrence of $\mathrm{HCC}$ after surgical resection is the major cause of death, as the incidence rate is approximately $70 \%$ at 5 years $[41,42]$. Therefore, an accurate prediction of prognosis prior to resection is crucial.

In previous studies, the authors developed a predictive ANN model [43-47] to predict therapeutic outcomes after surgical resection, and the ANN model was verified to be superior to the LR model and Cox proportional hazards regression model. Unfortunately, the ANN model cannot be used to select variables, which may decrease the predictive accuracy when some potentially clinically meaningful variables are overlooked. Similar to ANN, the BN model $[19,36]$ also cannot be used to select 


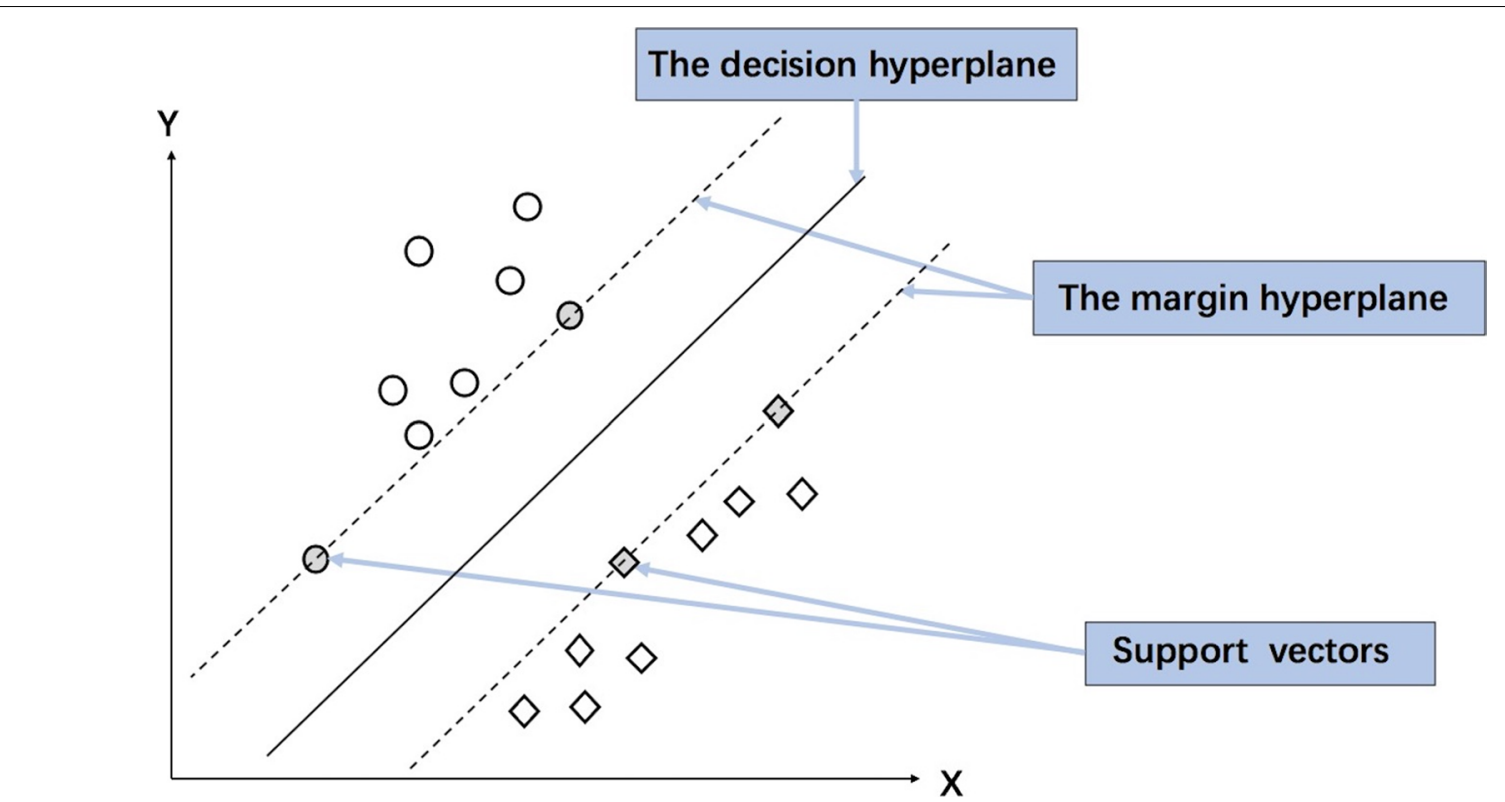

Fig. 2 Schematic diagram of a support vector machine (SVM). Although a decision hyperplane with maximal margin separates every sample into two classes, the support vector is the sample point on the margin hyperplane, which is the largest margin of classification under the constraints. The final SVM model is only related to support vectors

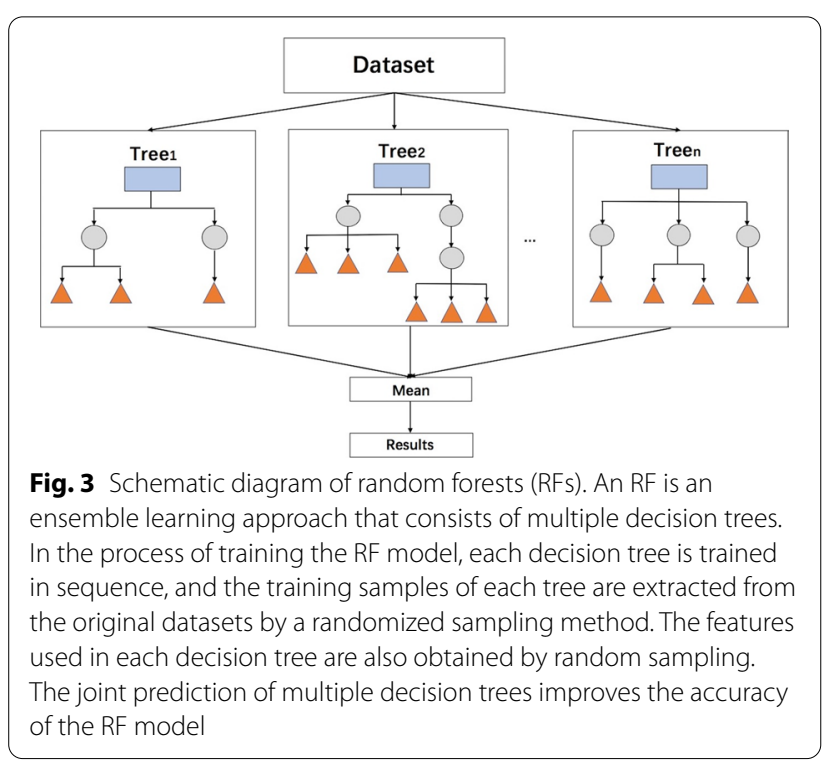

variables. The predictive variables within the $\mathrm{BN}$ model are based on the clinician's experience and knowledge, and the associated relationship between variables and outcome is not always clear; therefore, the performance of the BN model is generally confusing. Unlike ANN and $\mathrm{BN}, \mathrm{RF}$ and SVM can be used to either select variables or develop models [48-54]. Wang et al. [52] used the RF algorithm to select 30 radiomic features from $3144 \mathrm{MR}$ texture features and developed a predictive RSF model

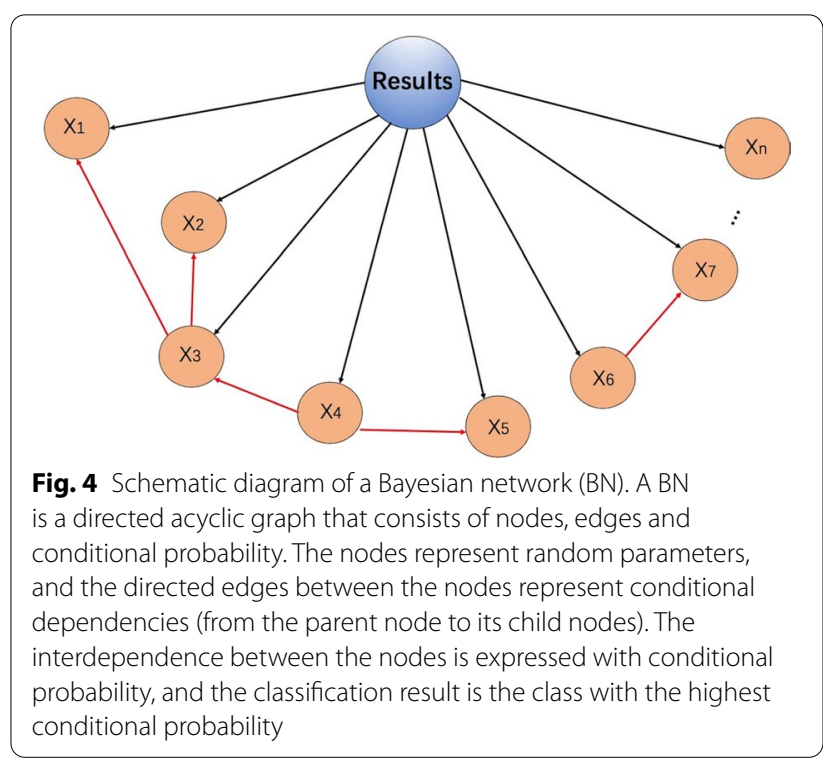

for the 5-year survival of HCC following surgical resection with an area under curve (AUC) of 0.980. In addition, Liao et al. developed an RF model [53] based on 46 features from whole slide images (WSIs), and the results showed comparable accuracy to the TNM staging system in predicting the prognosis of HCC patients after surgical resection. However, it should be noted that the sample size in the clinical study of HCC is usually small, and the SVM model is theoretically more suitable than other 


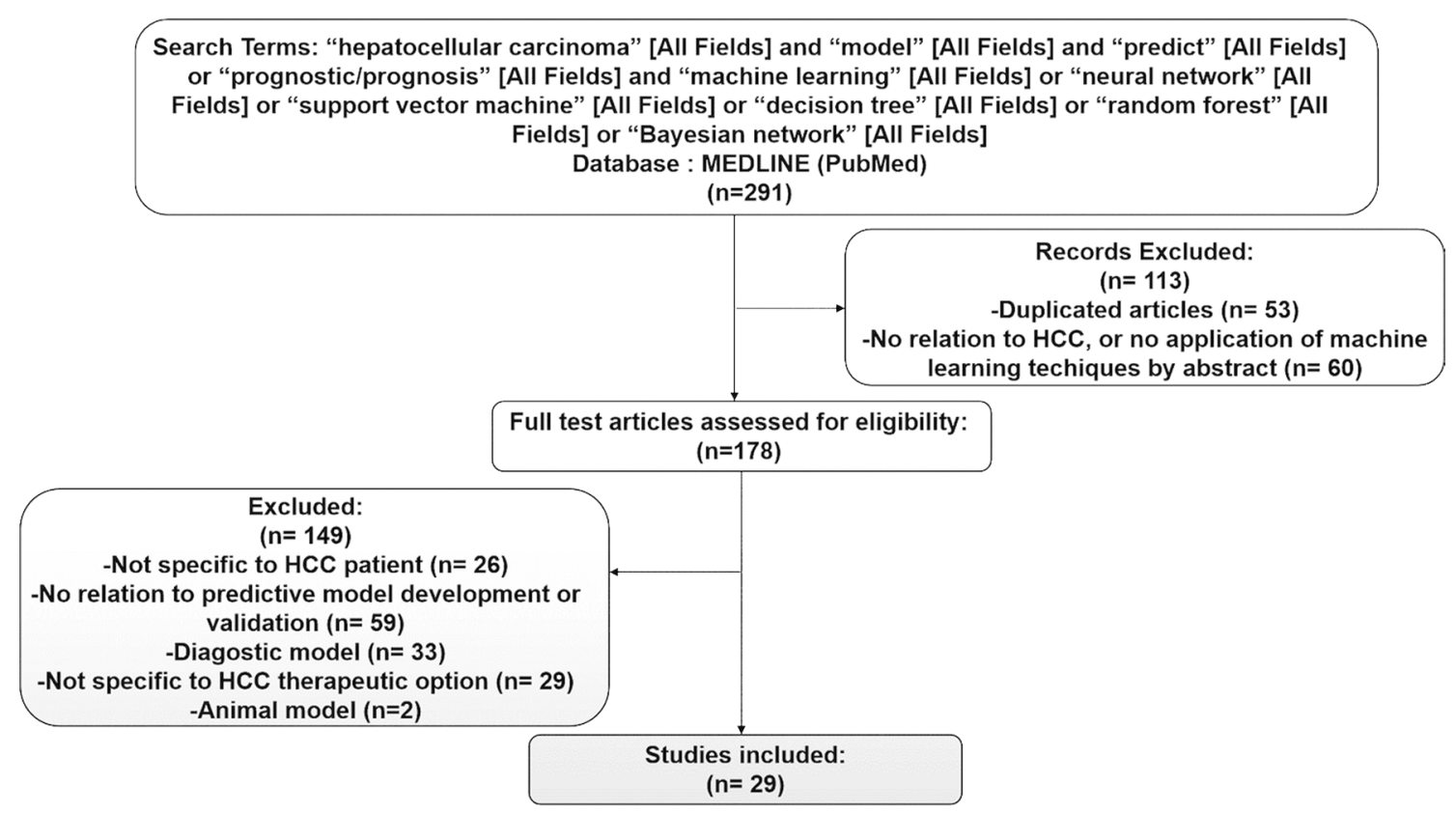

Fig. 5 Flowchart of the search strategy and selection of studies for inclusion

models. Xu et al. used an immunohistochemistry (IHC)based SVM algorithm [48] to predict the recurrence of 336 HCC patients after surgical resection. The SVM model finally selected 8 features from 49 features and had an accuracy of $82.1 \%$. In comparison to the abovementioned ML algorithms, the CNN algorithm has great convenience in establishing predictive models because they can be used not only to segment imaging but also to select parameters and to develop models [23, 55]. Wang et al. [23] used the CNN algorithm to extract high-level temporal and spatial features from multiphase CT imaging using an automatic mode, which showed high efficacy with an AUC of 0.825 for predicting the early recurrence of HCC. Nevertheless, the automatic mode based on the $\mathrm{CNN}$ algorithm requires high computational power and thus has limited use. The relevant papers are listed in Table 2.

\section{LT}

LT is regarded as an effective therapy in HCC patients who are within the Milan criteria, with a recurrence rate of $10-15 \%[38,56,57]$. Once post-LT HCC recurrence occurs, the prognosis is poor. Therefore, it is necessary to accurately identify HCC patients who will benefit from LT, thereby optimizing donor-recipient matching.

To our knowledge, ML-based analysis in predicting therapeutic outcomes for HCC after LT is rather limited. Marsh et al. $[58,59]$ developed an ANN model using seven clinical factors to predict the recurrence risk in HCC patients after LT, and the results showed that the discriminatory power was $70 \%$. However, in the combination of this model and other variables, such as genotyping for microsatellite mutations/deletions (TM-GTP), the predictive performance increased from 70 to $85 \%$. Rodriguez-Luna et al. [60] externally validated the ANN/TM-GTP model, and the discriminatory power was $89.5 \%$, while the sample size in the external validation cohort was too small, comprising only 19 patients; therefore, the predictive performance was less convincing. A multicenter study conducted by Nam et al. showed more convincing results [24] because they developed a DNN model and included a relatively large sample size, in which the training cohort was 563 and the validation cohort was 214 . Nevertheless, the predictive model should be based not only on the characteristics of receipts but also on donors. Therefore, precise receipt-donor matching is crucial to develop a predictive model. Zhang et al. [61] established an MLP model by including 14 characteristics of donors as well as recipients. The results showed that the c-statistics of the specific MLPs at 1,2, and 5 years were $0.909,0.888$, and 0.845 , respectively. However, the main weakness of this MLP model is the lack of external validation, and the generalization of this model needs to be further confirmed. The relevant papers are listed in Table 3. 
Table 2 Characteristics of ML-based predictive model of HCC patients after hepatectomy

\begin{tabular}{|c|c|c|c|c|c|c|}
\hline Author & Study type & No. of patients & Model & Outcomes & AUC/C-index & Conclusion \\
\hline Hamamoto [43], 1995 & $\begin{array}{l}\text { Retrospective Single } \\
\text { center }\end{array}$ & 65 & ANN & Death & - & $\begin{array}{l}\text { In the study for } \\
\text { predicting the died } \\
\text { of hepatic dysfunc- } \\
\text { tion, ANN predicted } \\
\text { the outcome of } \\
11 \text { patients in the } \\
\text { validation group } \\
\text { and achieved the } \\
\text { accuracy of } 100 \%\end{array}$ \\
\hline Ho [44], 2012 & $\begin{array}{l}\text { Retrospective Multi- } \\
\text { center }\end{array}$ & 427 & ANN and DT & 1,3,5-year DFS & $\begin{array}{l}\text { D: } 0.977 \text { and } 0.734 \\
\text { (1-year) } \\
0.989 \text { and } 0.825 \\
\text { ( } 3 \text {-year) } \\
0.963 \text { and } 0.675 \\
\text { (5-year) } \\
\text { V: } 0.777 \text { and } 0.718 \\
\text { (1-year) } \\
0.774 \text { and } 0.561 \\
\text { (3-year) } \\
0.864 \text { and } 0.627 \\
\text { (5-year) }\end{array}$ & $\begin{array}{l}\text { The ANN outperforms } \\
\text { DT in predicting DFS } \\
\text { in post-surgical HCC } \\
\text { patients }\end{array}$ \\
\hline Xu [48], 2012 & $\begin{array}{l}\text { Retrospective Multi- } \\
\text { center }\end{array}$ & 336 & SVM & RR & - & $\begin{array}{l}\text { The SVM based on } \\
\text { IHC features could } \\
\text { identify HCC patients } \\
\text { who are easily recur- } \\
\text { rence after surgery, } \\
\text { and the predictive } \\
\text { accuracy of SVM was } \\
66.5 \%\end{array}$ \\
\hline Chiu [45], 2013 & $\begin{array}{l}\text { Retrospective Multi- } \\
\text { center }\end{array}$ & 434 & ANN & $1,3,5$-year survival & $\begin{array}{l}\text { D: } 0.980 \text { (1-year) } \\
0.989 \text { (3-year) } \\
0.993 \text { (5-year) } \\
\text { V: } 0.875 \text { (1-year) } \\
0.798 \text { (3-year) } \\
0.810 \text { (5-year) }\end{array}$ & $\begin{array}{l}\text { The ANN model can } \\
\text { process a greater } \\
\text { number of predic- } \\
\text { tors and had better } \\
\text { accuracy than the } \\
\text { traditional LR model }\end{array}$ \\
\hline Qiao [46], 2014 & $\begin{array}{l}\text { Prospective Multi- } \\
\text { center }\end{array}$ & 725 & ANN & 5-year survival & $\begin{array}{l}\text { D: } 0.855 \\
\text { V: } 0.829\end{array}$ & $\begin{array}{l}\text { The ANN model out- } \\
\text { performs both Cox } \\
\text { and other staging } \\
\text { systems in predict- } \\
\text { ing survival in HCC } \\
\text { patients who have } \\
\text { received surgical } \\
\text { resection }\end{array}$ \\
\hline Cai [36], 2015 & $\begin{array}{l}\text { Retrospective Single } \\
\text { center }\end{array}$ & 299 & $\mathrm{BN}$ & 10-month survival & - & $\begin{array}{l}\text { The BN model had } \\
67.2 \% \text { of accuracy to } \\
\text { classify the survival } \\
\text { time of post-surgical } \\
\text { HCC patients }\end{array}$ \\
\hline Akai [49], 2018 & $\begin{array}{l}\text { Retrospective Single } \\
\text { center }\end{array}$ & 127 & RSF & DFS, OS & $\begin{array}{l}0.611 \\
0.701\end{array}$ & $\begin{array}{l}\text { RSF can predict the } \\
\text { individual risk for } \\
\text { each patient on DFS } \\
\text { and OS }\end{array}$ \\
\hline Wang [23], 2019 & $\begin{array}{l}\text { Retrospective Single } \\
\text { center }\end{array}$ & 167 & DCNN & RR & 0.825 & $\begin{array}{l}\text { Combined clinical } \\
\text { information and radi- } \\
\text { omics features can } \\
\text { effectively predict } \\
\text { early recurrence of } \\
\text { HCC patients }\end{array}$ \\
\hline
\end{tabular}


Table 2 (continued)

\begin{tabular}{|c|c|c|c|c|c|c|}
\hline Author & Study type & No. of patients & Model & Outcomes & AUC/C-index & Conclusion \\
\hline Kim [50], 2019 & $\begin{array}{l}\text { Retrospective Single } \\
\text { center }\end{array}$ & 167 & $\begin{array}{l}\text { RSF1* } \\
\text { RSF2** } \\
\text { RSF3*** }\end{array}$ & $\begin{array}{l}\text { Early recurrence } \\
\text { Lately recurrence }\end{array}$ & $\begin{array}{c}\text { Early recurrence: } \\
0.671 \text { (RSF1) } \\
0.679 \text { (RSF2) } \\
0.707 \text { (RSF3) } \\
\text { Early recurrence: } \\
0.737 \text { (RSF1) } \\
0.622 \text { (RSF2) } \\
0.716 \text { (RSF3) }\end{array}$ & $\begin{array}{l}\text { Compared to } \\
\text { another two RSF } \\
\text { models, combined } \\
\text { clinicopathologic- } \\
\text { radiomic RSF model } \\
\text { achieved the highest } \\
\text { predictive power for } \\
\text { the recurrence within } \\
2 \text { years after surgery } \\
\text { of HCC, and has fair } \\
\text { predictive perfor- } \\
\text { mance for lately } \\
\text { recurrence }\end{array}$ \\
\hline Xu [19], 2019 & $\begin{array}{l}\text { Retrospective Multi- } \\
\text { center }\end{array}$ & 1139 & $\begin{array}{l}\text { SVM } \\
\text { RF } \\
\text { BN }\end{array}$ & RR & - & $\begin{array}{l}\text { The accuracy of SVM, } \\
\text { RF and BN model } \\
\text { was } 0.46,0.48 \text { and } \\
0.56, \text { respectively, } \\
\text { in validation group } \\
\text { form another inde- } \\
\text { pendent institution. } \\
\text { The BN model could } \\
\text { contribute to HCC } \\
\text { recurrence research }\end{array}$ \\
\hline Mai [47], 2020 & $\begin{array}{l}\text { Retrospective Single } \\
\text { center }\end{array}$ & 353 & ANN & PHLF & $\begin{array}{l}0.880(\mathrm{D}) \\
0.876(\mathrm{~V})\end{array}$ & $\begin{array}{l}\text { The risk of severe PHIF } \\
\text { in HCC patients after } \\
\text { surgery based on } \\
\text { ANN model, can be } \\
\text { accurately divided } \\
\text { into } 3 \text { groups }\end{array}$ \\
\hline Saillard [55], 2020 & $\begin{array}{l}\text { Retrospective Multi- } \\
\text { center }\end{array}$ & 522 & $\begin{array}{l}\text { CNN1\# } \\
\text { CNN2\#\# }\end{array}$ & OS & $\begin{array}{l}\text { D: 0.75(CNN1) } \\
0.78(C N N 2) \\
\text { V: 0.68(CNN1) } \\
0.70(C N N 2)\end{array}$ & $\begin{array}{l}\text { Two CNN models } \\
\text { based on histological } \\
\text { features form WSIs } \\
\text { performed well for } \\
\text { predicting OS of HCC } \\
\text { patients after surgery, } \\
\text { and both CNN mod- } \\
\text { els outperformed } \\
\text { the CS that the score } \\
\text { included the relevant } \\
\text { clinical, biological } \\
\text { and pathological } \\
\text { features }\end{array}$ \\
\hline Schoenberg [51], 2020 & $\begin{array}{l}\text { Retrospective Single } \\
\text { center }\end{array}$ & 180 & RF & DFS & $\begin{array}{l}\text { D: } 0.766(0.627-0.904) \\
\vee: 0.788(0.658-0.919)\end{array}$ & $\begin{array}{l}\text { RF model based on } \\
\text { clinical and labora- } \\
\text { tory variables, can } \\
\text { accurately predict } \\
\text { DFS after surgery of } \\
\text { HCC }\end{array}$ \\
\hline Wang [52], 2020 & $\begin{array}{l}\text { Retrospective Multi- } \\
\text { center }\end{array}$ & 201 & RF & 5-year survival & $\begin{array}{l}\text { D: } 0.980 \\
\text { V: } 0.758\end{array}$ & $\begin{array}{l}\text { RAD model integrated } \\
\text { with RF in a valid } \\
\text { method to predict } \\
5 \text {-year survival of } \\
\text { post-operative HCC } \\
\text { patients }\end{array}$ \\
\hline Liao [53], 2020 & $\begin{array}{l}\text { Retrospective Multi- } \\
\text { center }\end{array}$ & 645 & RF & $1,3,5-Y$ survival & $\begin{array}{l}\text { V1: 0.626(1-year) } \\
0.658(3 \text {-year) } \\
0.581(5 \text {-year) } \\
\text { V2: } 0.600(1 \text {-year) } \\
0.595(3 \text {-year }) \\
0.566(5 \text {-year })\end{array}$ & $\begin{array}{l}\text { RF model based on } 46 \\
\text { histopathplogical } \\
\text { features, was able to } \\
\text { stratify post-surgical } \\
\text { patients of HCC into } \\
\text { long and short-term } \\
\text { groups. And the } \\
\text { RF model showed } \\
\text { similar accuracy with } \\
\text { TNM staging systems }\end{array}$ \\
\hline
\end{tabular}


Table 2 (continued)

\begin{tabular}{|c|c|c|c|c|c|c|}
\hline Author & Study type & No. of patients & Model & Outcomes & AUC/C-index & Conclusion \\
\hline Saito [54], 2020 & $\begin{array}{l}\text { Retrospective Multi- } \\
\text { center }\end{array}$ & 158 & SVM & RR & - & $\begin{array}{l}\text { The SVM model based } \\
\text { on digital pathologi- } \\
\text { cal images has the } \\
\text { accuracy of } 89.9 \% \\
\text { for prediction of } \\
\text { HCC recurrence after } \\
\text { surgery }\end{array}$ \\
\hline
\end{tabular}

*RSF1: clinicopathologic model using RSF; **RSF2: radiomic model using RSF; ***RSF3: combined clinicopathologic-radiomic model using RSF

\# CNN1: convolutional neural network model with automatically method to processing WSI imaging; \#\#CNN2: convolutional neural network model with an attention mechanism for WSI annotation by pathologist

$M L$ machine learning, $H C C$ hepatocellular carcinoma, $A U C$ area under the curve, $A N N$ artificial neural network, $D T$ decision tree, $D F S$ disease free survival, $D$ development cohort, $V$ validation cohort, SVM support vector machine, $R R$ recurrence rate, $I H C$ immunohistochemistry, $L R$ logistic regression, $B N$ bayesian network, $R S F$ recurrence-free survival, OS overall survival, $D C N N$ deep convolutional neural network, $R F$ random forest, $P H I F$ posthepatectomy liver failure, WSI whole-slide imaging, $R A D$ radiomic, TNM tumor node metastasis

Table 3 Characteristics of ML-based predictive model of HCC patients after transplantation

\begin{tabular}{|c|c|c|c|c|c|c|}
\hline Author & Study type & No. of patients & Model & Outcomes & AUC/C-statistics & Conclusion \\
\hline Marsh [58], 1997 & $\begin{array}{l}\text { Retrospective Single } \\
\text { center }\end{array}$ & 214 & ANN & 1,2,3-year RR & $\begin{array}{l}\text { D: } 0.962 \pm 0.01 \text { (1-year) } \\
0.944 \pm 0.05 \text { (2-year) } \\
0.952 \pm 0.04 \text { (3-year) } \\
\text { V: } 0.962 \pm 0.043 \text { (1-year) } \\
0.966 \pm 0.025 \text { (2-year) } \\
0.971 \pm 0.034 \text { (3-year) }\end{array}$ & $\begin{array}{l}\text { The ANN model can } \\
\text { identify post-LT HCC } \\
\text { patients with or with- } \\
\text { out recurrence }\end{array}$ \\
\hline Marsh [59], 2003 & $\begin{array}{l}\text { Retrospective Single } \\
\text { center }\end{array}$ & 214 & ANN & 1,2,3-year RR & $\begin{array}{l}0.98 \text { (1-year) } \\
0.95 \text { (2-year) } \\
0.96 \text { (3-year) }\end{array}$ & $\begin{array}{l}\text { The ANN has genotyping } \\
\text { as input parameter, } \\
\text { which is possible to } \\
\text { predict recurrence risk } \\
\text { of post-LT HCC }\end{array}$ \\
\hline $\begin{array}{l}\text { Rodriguez-Luna [60], } \\
2005\end{array}$ & $\begin{array}{l}\text { Retrospective Single } \\
\text { center }\end{array}$ & 19 & ANN & Recurrence & - & $\begin{array}{l}\text { This study validates the } \\
\text { result conducted by } \\
\text { Marsh et al., which } \\
\text { the model had the } \\
\text { discrimination power } \\
\text { of } 89.5 \%\end{array}$ \\
\hline Zhang [61], 2012 & $\begin{array}{l}\text { Retrospective Single } \\
\text { center }\end{array}$ & 290 & MLP & 1,2,5-year survival & $\begin{array}{l}0.909 \text { (1-year) } \\
0.888 \text { (2-year) } \\
0.845 \text { (5-year) }\end{array}$ & $\begin{array}{l}\text { The MLP model had } \\
\text { high accuracy to } \\
\text { predict post-transplant } \\
\text { mortality risk for HCC } \\
\text { recipients }\end{array}$ \\
\hline Nam [24], 2020 & $\begin{array}{l}\text { Retrospective Multi- } \\
\text { center }\end{array}$ & 563 & DNN & Recurrence & 0.75 & $\begin{array}{l}\text { The DNN model showed } \\
\text { promising predictive } \\
\text { performance and } \\
\text { outperformed other } \\
\text { traditional predictive } \\
\text { model to predict HCC } \\
\text { recurrence after LT }\end{array}$ \\
\hline
\end{tabular}

$M L$ machine learning, $H C C$ hepatocellular carcinoma, $A \cup C$ area under the curve, $A N N$ artificial neural network, $R R$ recurrence rate, $D$ development cohort, $V$ validation cohort, $L T$ liver transplantation, MLP multilayer perceptron, $D N N$ deep neural network

\section{Local ablation}

A string of image-guided percutaneous ablations encompasses a great variety of techniques, including radiofrequency ablation (RFA), microwave ablation (MWA), ethanol injection, and cryoablation [62-65]. As RFA is the most frequently used ablation modality for HCC $[66,67]$, the main topic addressed in this section is RFA. Although RFA has shown good feasibility in local tumor control for $\mathrm{HCC}$, complete ablation is slightly idealistic, and the relapse rate ranges from 49 to $63 \%$ [68]. When a recurrence of $\mathrm{HCC}$ after ablation arises, the proliferation and invasive ability of tumors are markedly increased.

Very few studies have used ML models to predict therapeutic outcomes in HCC patients in the setting of RFA. In a small sample analysis of $83 \mathrm{HCC}$ patients [69], an SVM model was used to analyze the relationship between 
clinical features and early post-RFA recurrence, and the results showed that the model had an AUC of 0.69. However, the predictive performance of the SVM model may decrease when a large number of variables are inputted. Therefore, it is essential to select the variable prior to establishing the SVM model. Conversely, the ANN algorithm cannot be used to select variables, while the key advantage of the ANN model is that it can process data with a large number of variables and samples. In the study of Wu et al. [70], a total of 15 variables were inputted into two ANN models for the prediction of 1-year disease-free survival (DFS) and 2-year DFS, and the performances of these two models were both excellent, with AUCs of 0.964 and 0.974, respectively. Unfortunately, both SVM and ANN models are immature because they lack external validation. The relevant papers are listed in Table 4.

\section{TACE}

Most HCC patients are typically diagnosed at intermediate or advanced stages when curative treatments cannot be applied [71, 72]. According to the Barcelona Clinic Liver Cancer (BCLC) staging system [73] and several treatment guidelines $[6,7]$, TACE is the gold standard for patients with intermediate-stage HCC. Since not all HCC patients can benefit from TACE [74, 75], a predictive model providing therapeutic outcome estimation prior to the procedure is urgently needed for clinical decision making.

Previous studies have constructed a variety of $\mathrm{ML}$ models with clinical and radiological variables for predicting the therapeutic outcome of HCC patients after TACE [25, 76-79]. Mähringer-Kunz et al. [76] used traditional imaging features, such as tumor size and tumor number, and other clinical variables to create an ANN model for predicting 1-year survival after TACE. Further, the results demonstrated that the predictive performance of this model was 0.77 in the training cohort and 0.83 in the validation cohort. However, imaging features are not always visible to the naked eye, and some tiny imaging features may be overlooked. Radiomics is an emerging discipline that can extract invisible imaging features such as statistic, shape and texture features from medical images. Abajian et al. [77] established an RF model and used semiautomatic 3D tumor segmenting software to extract several statistic and shape features from MR imaging. The results of their study demonstrated that the most valuable predictor of treatment response following TACE was relative tumor signal intensity on preTACE MR images, and the highest predictive accuracy of the RF model achieved $78 \%$. However, the quantitative imaging features in Abajian's study are too simple and cannot provide adequate information to predict the therapeutic outcome. Liu et al. [78] developed an SVM model with complex radiomic features. These complex radiomic features were first extracted by manual segmentation from static B-mode images, which included 181 statistic features, 13 tumor shape features, and 740 texture features. After extraction, the meaningful radiomic features were selected by the gradient boosted regression trees (GBRT) algorithm [78], and finally, the SVM model was established with an AUC of 0.81 in the internal validation cohort. Indeed, radiomic features can not only be extracted by manual or semiautomatic segmentation tools but can also be extracted automatically by $\mathrm{CNN}$ algorithms [25, 78, 79]. Morshid et al. [79] used a CNN-based segmentation protocol to extract a large number of shape and texture features from portal venous phase CT images. Based on these imaging features, an RF model was established, and the results showed that the RF model could accurately distinguish TACE-refractory patients with an AUC of 0.7331 [79]. In addition to extracting imaging features, the $\mathrm{CNN}$ algorithm can also be used to establish the predictive model $[25,78]$. Peng et al. [25] used the CNN algorithm to automatically extract the imaging features of $\mathrm{HCC}$ from $\mathrm{CT}$ images and established a predictive model of tumor response after TACE. Their study showed that the CNN models could

Table 4 Characteristics of ML-based predictive model after RFA

\begin{tabular}{|c|c|c|c|c|c|c|c|}
\hline Author & Study type & No. of patients & Modality & Model & Outcomes & AUC & Conclusion \\
\hline Liang [69], 2014 & Retrospective Single center & 83 & US guided & SVM & $\mathrm{RR}$ & 0.69 & $\begin{array}{l}\text { The SA + RF SVM method } \\
\text { had the best accuracy for } \\
\text { predicting high-risk recurrent } \\
\text { patients }\end{array}$ \\
\hline Wu [70], 2017 & Retrospective Single center & 431 & CT guided & MLP & 1,2-year DFS & $\begin{array}{l}\text { D: } 0.94 \text { (1-year) } \\
0.88 \text { (2-year) } \\
\text { V: } 0.77 \text { (1-year) } \\
0.72 \text { (2-year) }\end{array}$ & $\begin{array}{l}\text { The MLP-based model with } 15 \\
\text { clinical HCC relevant features } \\
\text { achieved satisfactory predic- } \\
\text { tion performance for 1-year } \\
\text { DFS }\end{array}$ \\
\hline
\end{tabular}


predict the complete response (CR), partial response $(\mathrm{PR})$, stable disease (SD) and progressive disease (PD) of HCC lesions with AUCs of 0.97, 0.96, 0.95, and 0.96, respectively. Similarly, Liu et al. [78] developed a CNN model to extract imaging features from dynamic contrast-enhanced ultrasound (CEUS) images and predict the objective response of $130 \mathrm{HCC}$ patients after TACE with an AUC of 0.93. The relevant papers are listed in Table 5.

\section{Sorafenib}

Sorafenib is the standard treatment for advanced-stage HCC. The median OS of sorafenib-treated HCC was 10.7 months and 6.5 months in two previous representative randomized controlled trials [80,81]. Because of the high cost and modest efficacy, a reliable predictive tool is necessary to assist clinicians in adjusting the daily management of sorafenib for such patients.

ML methods are not routinely used for predicting therapeutic outcomes in the treatment of sorafenib for HCC. Choi et al. [22] collected clinical and radiological data from 480 sorafenib-treated patients, and the important variable scores were used to select final parameters based on the RF algorithm. They found that the established model had a better predictive performance in time to progression (TTP) and overall survival (OS) than those of the Child-Pugh and Model for End-Stage Liver Disease (MELD) scores (0.746 vs 0.686 and 0.545 for TTP, 0.875 vs 0.777 and 0.682 for OS). However, this study lacks independent external validation. The relevant papers are listed in Table 6.

Table 5 Characteristics of ML-based predictive model of HCC patients after TACE

\begin{tabular}{|c|c|c|c|c|c|c|}
\hline Author & Study type & No. of patients & Model & Outcomes & AUC & Conclusion \\
\hline Abajian [77], 2018 & $\begin{array}{l}\text { Retrospective Single } \\
\text { center }\end{array}$ & 36 & RF & $\begin{array}{l}\text { Responders or non- } \\
\text { responders }\end{array}$ & - & $\begin{array}{l}\text { RF model combined with } \\
\text { MRI parameters may } \\
\text { be predicted tumor } \\
\text { response of post-TACE } \\
\text { HCC }\end{array}$ \\
\hline Morshid [79], 2019 & $\begin{array}{l}\text { Retrospective Single } \\
\text { center }\end{array}$ & 105 & $\mathrm{RF}$ & $\begin{array}{l}\text { TACE-susceptible or } \\
\text { TACE-refractory }\end{array}$ & 0.733 & $\begin{array}{l}\text { The accuracy of RF model } \\
\text { using a combination } \\
\text { of clinical parameters } \\
\text { plus quantitative image } \\
\text { features was higher than } \\
\text { the RF model based on } \\
\text { the clinical parameters } \\
\text { alone, in the study of } \\
\text { predicting HCC response } \\
\text { to TACE }\end{array}$ \\
\hline $\begin{array}{l}\text { Mähringer-Kunz [76], } \\
2020\end{array}$ & $\begin{array}{l}\text { Retrospective Single } \\
\text { center }\end{array}$ & 282 & ANN & 1-year survival & $\begin{array}{l}V: 0.77 \pm 0.13 \\
D: 0.83 \pm 0.06\end{array}$ & $\begin{array}{l}\text { The ANN model had a } \\
\text { promising performance } \\
\text { at predicting HCC } \\
\text { patient survival after } \\
\text { TACE and outperformed } \\
\text { the traditional scoring } \\
\text { systems }\end{array}$ \\
\hline Peng [25], 2020 & $\begin{array}{l}\text { Retrospective Multi- } \\
\text { center }\end{array}$ & 798 & CNN & $C R, P R, S D, P D$ & $\begin{array}{l}\text { D: } 0.97(C R) \\
0.96(P R) \\
0.95(\mathrm{SD}) \\
0.96(\mathrm{PD}) \\
\mathrm{V}: 0.98(\mathrm{CR}) \\
0.96(\mathrm{PR}) \\
0.95(\mathrm{SD}) \\
0.94(\mathrm{PD})\end{array}$ & $\begin{array}{l}\text { The CNN model presented } \\
\text { a good performance for } \\
\text { predicting the outcome } \\
\text { of TACE }\end{array}$ \\
\hline Liu [78], 2020 & $\begin{array}{l}\text { Retrospective Single } \\
\text { center }\end{array}$ & 138 & $\begin{array}{l}\text { CNN } \\
\text { SVM1* } \\
\text { SVM2\# }\end{array}$ & ORR & $\begin{array}{l}\text { D: } 0.98 \text { (CNN) } \\
0.84 \text { (SVM1) } \\
0.82 \text { (SVM2) } \\
\text { V: } 0.93 \text { (CNN) } \\
0.80 \text { (SVM1) } \\
0.81 \text { (SVM2) }\end{array}$ & $\begin{array}{l}\text { CNN is better in predicting } \\
\text { treatment response over } \\
\text { SVM in HCC patients } \\
\text { treated with TACE }\end{array}$ \\
\hline
\end{tabular}

*SVM1: radiomics-based time-intensity curve of CEUS model using SVM; "SVM2: radiomics-based B-Mode images model using SVM

$M L$ machine learning, HCC hepatocellular carcinoma, TACE transarterial chemoembolization, $A U C$ area under the curve, $R F$ random forest, $M R I$ magnetic resonance imaging, $A N N$ artificial neural network, $D$ development cohort, $V$ validation cohort, $C N N$ convolutional neural network, $C R$ complete response, $P R$ partial response, $S D$ stable disease, $P D$ progressive disease, SVM support vector machine, ORR objective response rate, CEUS contrast-enhanced ultrasound 
Table 6 Characteristics of ML-based predictive model of HCC patients after treatment of sorafenib

\begin{tabular}{|c|c|c|c|c|c|c|}
\hline Author & Study type & No. of patients & Model & Outcomes & C-index & Conclusion \\
\hline Choi [22], 2017 & Retrospective Single center & 480 & LR & TTP and OS & $\begin{array}{l}\text { D: } 0.669 \text { (TTP) } \\
0.809 \text { (OS) } \\
\text { V: } 0.746 \text { (TTP) } \\
0.875 \text { (OS) }\end{array}$ & $\begin{array}{l}\text { The prognostic factors selected by RF algorithm } \\
\text { were used to develop an excellent predictive } \\
\text { model by LR approach for the prediction of } \\
\text { therapeutic outcome after sorafenib }\end{array}$ \\
\hline
\end{tabular}

$M L$ machine learning, HCC hepatocellular carcinoma, $L R$ logistic regression, TTP time to progression, OS overall survival, $D$ development cohort, $V$ validation cohort, $R F$ random forest

Future perspectives in ML for the prognostic study of HCC Currently, the ML model for predicting the therapeutic outcome of HCC is usually based on multivariate predictors, such as demographic, clinical, radiological, pathologic and genetic parameters. Selecting the final predictors is a considerable challenge in traditional statistical models because traditional statistical methods may lose some important information. The ML model can include more variables, and it may become a promising protocol over the traditional statistical model. In addition, the ML algorithm can extract and select radiomic features that are invisible to the naked eye, and those novel variables may provide promising predictive value compared with simple radiological parameters (tumor size and tumor number, etc.).

The most important challenge in the ML approach is the accurate selection of algorithms to create the predictive model with external validation for the model. On the one hand, certain types of ML models are favored for specific types of data, such as CNNs for imaging data and SVMs for small sample size data. The ML model should be selected by a thoughtful study design. On the other hand, as there is a need for clinical reality in the future, appropriate external validation should be used to confirm the generalization ability. Due to the lack of a commonly accepted design of $\mathrm{ML}$ predictive models for the prognostic study of $\mathrm{HCC}$, it may be possible that the current ML model is not the best one available.

\section{Conclusion}

ML algorithms can automatically extract imaging features and identify optimal subsets of features from large data sets, particularly when combined with radiomics analysis. Relative to traditional statistical models, ML models demonstrate improved predictive performance in the prognostic study of HCC. Regrettably, most existing ML predictive models lack external validation, which is an obstacle to serving HCC patients as personalized predictive tools. Although most current ML algorithms are preliminary, this promising method will be widely accepted in clinical practice in the future.
Abbreviations

AUC: Area under curve; ANN: Artificial neural network; BCLC: Barcelona Clinic Liver Cancer; BN: Bayesian network; CR: Complete response; CPT: Conditional probability table; CEUS: Contrast-enhanced ultrasound; CNN: Convolutional neural network; DT: Decision tree; DNN: Deep neural network; DFS: Diseasefree survival; GBRT: Gradient boosted regression trees; HCC: Hepatocellular carcinoma; IHC: Immunohistochemistry; LT: Liver transplantation; LR: Logistic regression; ML: Machine learning; MWA: Microwave ablation; MELD: Model for End-Stage Liver Disease; MLP: Multilayer perceptron; OS: Overall survival; PR: Partial response; PD: Progressive disease; RFA: Radiofrequency ablation; RF: Random forest; RSF: Random survival forests; RNN: Recurrent neural network; SD: Stable disease; SVM: Support vector machine; TTP: Time to progression; TACE: Transarterial chemoembolization; WSI: Whole slide image.

\section{Authors' contributions}

Z-MZ wrote the manuscript, D-HC and HL revised the manuscript. Y-DX provided the concept. D-HC and Y-DX edited the manuscript Y-DX was the major contributor to this manuscript. All authors read and approved the final manuscript.

Funding

Not applicable.

Availability of data and materials

Not applicable.

Ethics approval and consent to participate

Not applicable.

Consent for publication

Not applicable.

Competing interests

There are no competing interests.

\section{Author details}

1 Department of Radiology, The Second Xiangya Hospital of Central South University, No.139 Middle Renmin Road, Changsha 410011, China. ${ }^{2}$ Department of Diagnostic and Interventional Radiology, University Hospital Heidelberg, 69120 Heidelberg, Germany.

Received: 24 November 2020 Accepted: 15 February 2021

Published online: 06 March 2021

\section{References}

1. Ameli S, Shaghaghi M, Ghasabeh MA et al (2020) Role of baseline volumetric functional MRI in predicting histopathologic grade and patients' survival in hepatocellular carcinoma. Eur Radiol 30:3748-3758

2. Bray F, Ferlay J, Soerjomataram I, Siegel RL, Torre LA, Jemal A (2018) Global cancer statistics 2018: GLOBOCAN estimates of incidence and mortality worldwide for 36 cancers in 185 countries. CA Cancer J Clin 68:394-424

3. Tang A, Hallouch O, Chernyak V, Kamaya A, Sirlin CB (2018) Epidemiology of hepatocellular carcinoma: target population for surveillance and diagnosis. Abdom Radiol (NY) 43:13-25

4. Kudo M, Izumi N, Kokudo N et al (2011) Management of hepatocellular carcinoma in Japan: Consensus-Based Clinical Practice Guidelines 
proposed by the Japan Society of Hepatology (JSH) 2010 updated version. Dig Dis 29:339-364

5. Omata M, Cheng AL, Kokudo N et al (2017) Asia-Pacific clinical practice guidelines on the management of hepatocellular carcinoma: a 2017 update. Hepatol Int 11:317-370

6. European Association for the Study of the Liver, European Association for the Study of the Liver (2018) EASL Clinical Practice Guidelines: management of hepatocellular carcinoma. J Hepatol 69:182-236

7. Heimbach JK, Kulik LM, Finn RS et al (2018) AASLD guidelines for the treatment of hepatocellular carcinoma. Hepatology 67:358-380

8. Khalaf MH, Sundaram V, AbdelRazek Mohammed MA et al (2019) A predictive model for postembolization syndrome after transarterial hepatic chemoembolization of hepatocellular carcinoma. Radiology 290:254-261

9. Yoo J, Lee MW, Lee DH, Lee JH, Han JK (2020) Evaluation of a serum tumour marker-based recurrence prediction model after radiofrequency ablation for hepatocellular carcinoma. Liver Int 40:1189-1200

10. Labeur TA, Berhane S, Edeline J et al (2020) Improved survival prediction and comparison of prognostic models for patients with hepatocellular carcinoma treated with sorafenib. Liver Int 40:215-228

11. Schobert IT, Savic LJ, Chapiro J et al (2020) Neutrophil-to-lymphocyte and platelet-to-lymphocyte ratios as predictors of tumor response in hepatocellular carcinoma after DEB-TACE. Eur Radiol 30:5663-5673

12. Nam JY, Choe AR, Sinn DH et al (2020) A differential risk assessment and decision model for Transarterial chemoembolization in hepatocellular carcinoma based on hepatic function. BMC Cancer 20:504

13. Erickson BJ, Korfiatis $P$, Akkus Z, Kline TL (2017) Machine learning for medical imaging. Radiographics 37:505-515

14. Mokrane FZ, Lu L, Vavasseur A et al (2020) Radiomics machine-learning signature for diagnosis of hepatocellular carcinoma in cirrhotic patients with indeterminate liver nodules. Eur Radiol 30:558-570

15. Hosny A, Parmar C, Quackenbush J, Schwartz LH, Aerts HJWL (2018) Artificial intelligence in radiology. Nat Rev Cancer 18:500-510

16. Wakabayashi T, Ouhmich F, Gonzalez-Cabrera C et al (2019) Radiomics in hepatocellular carcinoma: a quantitative review. Hepatol Int 13:546-559

17. Santos MS, Abreu PH, García-Laencina PJ, Simão A, Carvalho A (2015) A new cluster-based oversampling method for improving survival prediction of hepatocellular carcinoma patients. J Biomed Inform 58:49-59

18. Divya R, Radha P (2019) An optimized HCC recurrence prediction using APO algorithm multiple time series clinical liver cancer dataset. J Med Syst 43:193

19. Xu D, Sheng JQ, Hu PJ, Huang TS, Lee WC (2019) Predicting hepatocellular carcinoma recurrences: a data-driven multiclass classification method incorporating latent variables. J Biomed Inform 96:103237

20. Liu X, Hou Y, Wang X et al (2020) Machine learning-based development and validation of a scoring system for progression-free survival in liver cancer. Hepatol Int 14:567-576

21. Ji GW, Zhu FP, Xu Q et al (2019) Machine-learning analysis of contrastenhanced CT radiomics predicts recurrence of hepatocellular carcinoma after resection: a multi-institutional study. EBioMedicine 50:156-165

22. Choi GH, Han S, Shim JH et al (2017) Prognostic scoring models for patients undergoing sorafenib treatment for advanced stage hepatocellular carcinoma in real-life practice. Am J Clin Oncol 40:167-174

23. Wang W, Chen $\mathrm{Q}$, I wamoto $Y$ et al (2019) Deep learning-based radiomics models for early recurrence prediction of hepatocellular carcinoma with multi-phase CT images and clinical data. Annu Int Conf IEEE Eng Med Biol Soc 2019:4881-4884

24. Nam JY, Lee JH, Bae J et al (2020) Novel model to predict HCC recurrence after liver transplantation obtained using deep learning: a multicenter study. Cancers (Basel) 12:E2791

25. Peng J, Kang S, Ning Z et al (2020) Residual convolutional neural network for predicting response of transarterial chemoembolization in hepatocellular carcinoma from CT imaging. Eur Radiol 30:413-424

26. Cross SS, Harrison RF, Kennedy RL (1995) Introduction to neural networks. Lancet 346:1075-1079

27. Lee JG, Jun S, Cho YW et al (2017) Deep learning in medical imaging: general overview. Korean J Radiol 18:570-584

28. Anwar SM, Majid M, Qayyum A, Awais M, Alnowami M, Khan MK (2018) Medical image analysis using convolutional neural networks: a review. J Med Syst 42:226

29. Brehar R, Mitrea DA, Vancea F et al (2020) Comparison of deep-learning and conventional machine-learning methods for the automatic recognition of the hepatocellular carcinoma areas from ultrasound images. Sensors (Basel) 20:3085

30. Cortes C, VapnikV (1995) Support-vector networks. Mach Learn 20:273-297

31. Podgorelec V, Kokol P, Stiglic B, Rozman I (2002) Decision trees: an overview and their use in medicine. J Med Syst 26:445-463

32. Breiman L (2001) Random forests. Mach Learn 45:5-32

33. Uddin S, Khan A, Hossain ME, Moni MA (2019) Comparing different supervised machine learning algorithms for disease prediction. BMC Med Inform Decis Mak 19:281

34. Ishwaran H, Gerds TA, Kogalur UB, Moore RD, Gange SJ, Lau BM (2014) Random survival forests for competing risks. Biostatistics 15:757-773

35. Weber P, Medina-Oliva G, Simon C, Lung B (2012) Overview on Bayesian networks applications for dependability, risk analysis and maintenance areas. Eng Appl Artif Intel 25:671-682

36. Cai ZQ, Si SB, Chen C et al (2015) Analysis of prognostic factors for survival after hepatectomy for hepatocellular carcinoma based on a Bayesian network. PLOS ONE 10:e0120805

37. Keating GM (2017) Sorafenib: a review in hepatocellular carcinoma. Target Oncol 12:243-253

38. Berumen J, Hemming A (2018) Liver transplantation for hepatocellular carcinoma. Abdom Radiol (NY) 43:185-192

39. Narsinh KH, Duncan DP, Newton IG, Minocha J, Rose SC (2018) Liverdirected therapy for hepatocellular carcinoma. Abdom Radiol (NY) 43:203-217

40. Langenbach MC (2019) RFA vs resection of HCC: exploring the past to improve the future. Eur Radiol 29:2677-2678

41. Bruix J, Reig M, Sherman M (2016) Evidence-based diagnosis, staging, and treatment of patients with hepatocellular carcinoma. Gastroenterology 150:835-853

42. Kulik L, El-Serag HB (2019) Epidemiology and management of hepatocellular carcinoma. Gastroenterology 156:477-491

43. Hamamoto I, Okada S, Hashimoto T, Wakabayashi H, Maeba T, Maeta H (1995) Prediction of the early prognosis of the hepatectomized patient with hepatocellular carcinoma with a neural network. Comput Biol Med 25:49-59

44. Ho WH, Lee KT, Chen HY, Ho TW, Chiu HC (2012) Disease-free survival after hepatic resection in hepatocellular carcinoma patients: a prediction approach using artificial neural network. PLoS ONE 7:e29179

45. Chiu HC, Ho TW, Lee KT, Chen HY, Ho WH (2013) Mortality predicted accuracy for hepatocellular carcinoma patients with hepatic resection using artificial neural network. Sci World J 2013:201976

46. Qiao G, Li J, Huang A, Yan Z, Lau WY, Shen F (2014) Artificial neural networking model for the prediction of post-hepatectomy survival of patients with early hepatocellular carcinoma. J Gastroenterol Hepatol 29:2014-2020

47. Mai RY, Lu HZ, Bai T et al (2020) Artificial neural network model for preoperative prediction of severe liver failure after hemihepatectomy in patients with hepatocellular carcinoma. Surgery 168:643-652

48. Xu J, Ding T, He Q et al (2012) An in situ molecular signature to predict early recurrence in hepatitis B virus-related hepatocellular carcinoma. J Hepatol 57:313-321

49. Akai H, Yasaka K, Kunimatsu A et al (2018) Predicting prognosis of resected hepatocellular carcinoma by radiomics analysis with random survival forest. Diagn Interv Imaging 99:643-651

50. Kim S, Shin J, Kim DY, Choi GH, Kim MJ, Choi JY (2019) Radiomics on gadoxetic acid-enhanced magnetic resonance imaging for prediction of postoperative early and late recurrence of single hepatocellular carcinoma. Clin Cancer Res 25:3847-3855

51. Schoenberg MB, Bucher JN, Koch D et al (2020) A novel machine learning algorithm to predict disease free survival after resection of hepatocellular carcinoma. Ann Transl Med 8:434

52. Wang XH, Long LH, Cui Y et al (2020) MRI-based radiomics model for preoperative prediction of 5-year survival in patients with hepatocellular carcinoma. Br J Cancer 122:978-985

53. Liao H, Xiong T, Peng J et al (2020) Classification and prognosis prediction from histopathological images of hepatocellular carcinoma by a fully automated pipeline based on machine learning. Ann Surg Oncol 27:2359-2369

54. Saito A, Toyoda H, Kobayashi M et al (2020) Prediction of early recurrence of hepatocellular carcinoma after resection using digital pathology 
images assessed by machine learning [published online ahead of print, 2020 Sep 18]. Mod Pathol. https://doi.org/10.1038/s41379-020-00671-z

55. Saillard C, Schmauch B, Laifa O et al (2020) Predicting survival after hepatocellular carcinoma resection using deep-learning on histological slides [published online ahead of print, 2020 Feb 28]. Hepatology. https://doi. org/10.1002/hep.31207

56. Sapisochin G, Bruix J (2017) Liver transplantation for hepatocellular carcinoma: outcomes and novel surgical approaches. Nat Rev Gastroenterol Hepatol 14:203-217

57. Kim B, Kahn J, Terrault NA (2020) Liver transplantation as therapy for hepatocellular carcinoma. Liver Int 40(Suppl 1):116-121

58. Marsh JW, Dvorchik I, Subotin M et al (1997) The prediction of risk of recurrence and time to recurrence of hepatocellular carcinoma after orthotopic liver transplantation: a pilot study. Hepatology 26:444-450

59. Marsh JW, Finkelstein SD, Demetris AJ et al (2003) Genotyping of hepatocellular carcinoma in liver transplant recipients adds predictive power for determining recurrence-free survival. Liver Transpl 9:664-671

60. Rodriguez-Luna H, Vargas HE, Byrne T, Rakela J (2005) Artificial neural network and tissue genotyping of hepatocellular carcinoma in liver-transplant recipients: prediction of recurrence. Transplantation 79:1737-1740

61. Zhang M, Yin F, Chen B et al (2012) Mortality risk after liver transplantation in hepatocellular carcinoma recipients: a nonlinear predictive model. Surgery 151:889-897

62. Ren Y, Cao Y, Ma H et al (2019) Improved clinical outcome using transarterial chemoembolization combined with radiofrequency ablation for patients in Barcelona clinic liver cancer stage A or B hepatocellular carcinoma regardless of tumor size: results of a single-center retrospective case control study. BMC Cancer 19:983

63. Liu B, Long J, Wang W et al (2019) Predictive factors of treatment outcomes after percutaneous ablation of hepatocellular carcinoma in the caudate lobe: a retrospective study. BMC Cancer 19:699

64. Kim R, Kang TW, Cha DI et al (2019) Percutaneous cryoablation for perivascular hepatocellular carcinoma: therapeutic efficacy and vascular complications. Eur Radiol 29:654-662

65. Chai Y, Li K, Zhang C, Chen S, Ma K (2019) The short-term efficacy of no-touch radiofrequency ablation in treating cirrhosis-based small hepatocellular carcinoma. BMC Cancer 19:497

66. Forner A, Reig M, Bruix J (2018) Hepatocellular carcinoma. Lancet 391:1301-1314

67. Lee DH, Lee JM, Kim PN et al (2019) Whole tumor ablation of locally recurred hepatocellular carcinoma including retained iodized oil after transarterial chemoembolization improves progression-free survival. Eur Radiol 29:5052-5062

68. Nault JC, Sutter O, Nahon P, Ganne-Carrié N, Séror O (2018) Percutaneous treatment of hepatocellular carcinoma: state of the art and innovations. J Hepatol 68:783-797

69. Liang JD, Ping XO, Tseng YJ, Huang GT, Lai F, Yang PM (2014) Recurrence predictive models for patients with hepatocellular carcinoma after radiofrequency ablation using support vector machines with feature selection methods. Comput Methods Programs Biomed 117:425-434

70. Wu CF, Wu YJ, Liang PC, Wu CH, Peng SF, Chiu HW (2017) Disease-free survival assessment by artificial neural networks for hepatocellular carcinoma patients after radiofrequency ablation. J Formos Med Assoc 116:765-773

71. Zhang ZS, Li HZ, Ma C, Xiao YD (2019) Conventional versus drug-eluting beads chemoembolization for infiltrative hepatocellular carcinoma: a comparison of efficacy and safety. BMC Cancer 19:1162

72. Liang B, Xiang H, Ma C et al (2020) Comparison of chemoembolization with CalliSpheres ${ }^{\circledR}$ microspheres and conventional chemoembolization in the treatment of hepatocellular carcinoma: a multicenter retrospective study. Cancer Manag Res 12:941-956

73. Llovet JM, Brú C, Bruix J (1999) Prognosis of hepatocellular carcinoma: the BCLC staging classification. Semin Liver Dis 19:329-338

74. Sieghart W, Hucke F, Peck-Radosavljevic M (2015) Transarterial chemoembolization: modalities, indication, and patient selection. J Hepatol 62:1187-1195

75. Lencioni R, de Baere T, Soulen MC, Rilling WS, Geschwind JF (2016) Lipiodol transarterial chemoembolization for hepatocellular carcinoma: a systematic review of efficacy and safety data. Hepatology 64:106-116

76. Mähringer-Kunz A, Wagner F, Hahn F et al (2020) Predicting survival after transarterial chemoembolization for hepatocellular carcinoma using a neural network: a Pilot Study. Liver Int 40:694-703

77. Abajian A, Murali N, Savic LJ et al (2018) Predicting treatment response to intra-arterial therapies for hepatocellular carcinoma with the use of supervised machine learning-an artificial intelligence concept. J Vasc Interv Radiol 29:850-857

78. Liu D, Liu F, Xie X et al (2020) Accurate prediction of responses to transarterial chemoembolization for patients with hepatocellular carcinoma by using artificial intelligence in contrast-enhanced ultrasound. Eur Radiol 30:2365-2376

79. Morshid A, Elsayes KM, Khalaf AM et al (2019) A machine learning model to predict hepatocellular carcinoma response to transcatheter arterial chemoembolization. Radiol Artif Intell 1:e180021

80. Faivre S, Raymond E, Boucher E et al (2009) Safety and efficacy of sunitinib in patients with advanced hepatocellular carcinoma: an open-label, multicentre, phase II study. Lancet Oncol 10:794-800

81. Cheng AL, Kang YK, Chen Z et al (2009) Efficacy and safety of sorafenib in patients in the Asia-Pacific region with advanced hepatocellular carcinoma: a phase III randomised, double-blind, placebo-controlled trial. Lancet Oncol 10:25-34

\section{Publisher's Note}

Springer Nature remains neutral with regard to jurisdictional claims in published maps and institutional affiliations.

\section{Submit your manuscript to a SpringerOpen ${ }^{\circ}$ journal and benefit from:}

- Convenient online submission

- Rigorous peer review

- Open access: articles freely available online

- High visibility within the field

- Retaining the copyright to your article

Submit your next manuscript at $\boldsymbol{\nabla}$ springeropen.com 